\title{
Construction and Application of Moodle-based Online Learning Community between Urban and Rural Students
}

\author{
Fei LI
}

\begin{abstract}
Urban and rural online learning communities can share high-quality education resources. The existing researches mainly focus on the construction of online learning community between urban and rural teachers (T-T), while few focus on the construction of online learning community between urban and rural students (S-S), and T-S. This paper aims to use Moodle platform to build urban and rural students' online learning community, to achieve the formation of online learning community between urban and rural teachers (T-T), students (S-S), and T-S, so as to promote the sharing of urban and rural education resources. At the same time, the network teaching provided by the platform can break through the traditional teacher centered indoctrination teaching mode and establish a modern student-centered teaching mode, so as to cultivate students' independent learning, innovation and self-discipline consciousness, expand their horizons and lay a good foundation for urban and rural students to experience different cultures.
\end{abstract}

Keywords: Moodle; online learning community; urban and rural students

\section{INTRODUCTION}

According to Education Informatization Decade Development Plan (2011-2020) of the Ministry of Education, it is noted that we should actively use information technology to carry out heuristic, exploratory, communicative, participatory teaching to encourage the dynamic evaluation and explore the new teaching model centered on learners. It aims to advocate network interschool collaborative learning and improve the teaching level of information technology. The plan encourages students to use information to take the initiative to learn, promote autonomous learning, as well as cooperative learning; it also trains them to develop interests and good habits utilizing information technology as a result of higher learning effects; it enhances students to ask questions, analyze and solve problems in the network environment [1] This policy provides new hope for strengthening the communication between urban and rural students and promoting the sustainable development of rural students.

The main goal of this paper is to build a network learning community for urban and rural students, to achieve the formation of network learning community between urban and rural teachers (T-T), students (S-S), and T-S. Therefore, the author uses Moodle, one of the most popular course management systems (CMS) in the world, to build an online learning community for urban and rural students based on Moodle.

This paper first introduces Moodle platform, online learning community and other related concepts, then analyzes the significance of building a Moodle platform based online learning community for urban and rural students, and finally analyzes the design principle, implementation form, main function positioning and model of the platform. The online learning community of urban and rural students based on Moodle platform can not only narrow the education gap between urban and rural areas, but also enable urban and rural students to obtain highquality education resources and further promote the fair development of education. Moreover, the platform can also cultivate students' ability of autonomous learning and collaborative learning, and constantly enhance the actual teaching effect.

\section{TERMS AND CONCEPTS 2.1 On Moodle Platform}

Moodle (short for Modular Object-Oriented Dynamic Learning Environment), with a variety of language versions including Simplified Chinese, can be applied in education, teaching, training and management to support Online teaching, Group discussions, Collaborative learning and autonomous learning and other teaching models. For it is powerful, easy to master and use and develops rapidly, Moodle has been widely used in many countries at present [2].

Moodle, a curriculum management system (CMS) developed by Martin Dougiamas, an Australian teacher, is based on the philosophy of social constructivism education. Pan Juan et al. believe that social constructivism emphasizes the meaning of social construction, social learning setting, social interaction, collaboration and activities. It emphasizes that knowledge is not passed by teachers, but that it is constructed through active interaction by learners with others in a richly socio-cultural context [3]. Moodle platform can effectively manage multiple courses and support online testing, surveys and voting. It also can test the results of the analysis and facilitate teachers and students to conduct collaborative learning in groups by using discussion forums, website short message and chat rooms [4].

\subsection{Online Learning Community}

The term "community" is initially used in disciplinary area as a concept of sociology, and its basic meaning is any form of organic organization based on cooperative relationships. After that, Dewey introduced the "community" into the educational teaching setting in Democratism and Education and put forward the concept of "learning community" to embody the concept of education as a way of living with an initiative to realize individual lifelong development beyond the limitations of education. Learning community takes learners' shared vision as a starting point, emphasizes the social learning setting and the social construction of knowledge and meaning to foster experience exchange and negotiation 
among learners centering on the growth of learners in social culture [5]. With the development of computer technology and network technology, the concept of "Online learning community" has been formed in the field of education. It has a positive effect on promoting the construction of social knowledge, improving the quality of network teaching, and cultivating students' innovative ability and cooperative spirit [6].

Online Learning Community, also known as the eLearning Online Learning Community or the Virtual Learning Community, is a learning group built by learners and facilitators (teachers, experts, instructors, etc.) in a virtual network environment, with a variety of interactive, collaborative and shared software tools. In the group, all participants are equal, and regular communication, exchange, sharing are combined together to achieve the learning goal. In the process, the mutual trust and mutual understanding of the relationship between the tacit relationships between members are established. To be exact, it is called some kind of "community culture", [7]. Online learning community between urban and rural students is a case of network virtual learning group built by computer information technology.

\section{SIGNIFICANCE}

\subsection{To Promote the Integration of Urban and Rural Education}

National Medium and Long-term Education Reform and Development Plan (2010-2020) pointed out that we should make efforts "to establish basic public education service system covering urban and rural areas, to realize the equalization of public education services, and to narrow the regional gap" as a strategy for the development of education objectives. The plan put forward the development task "to speed up the narrowing of urban and rural areas, to establish compulsory education development mechanism of urban and rural integration" [8]. However, owing to urban and rural dual division, there exist some differences about urban and rural education in the spatial layout, resource quantity and quality, hindering the integration of urban and rural education. Han Qinglin notes that the integration of urban and rural education needs to co-ordinate the equalization of urban and rural education and public services, to explore and improve the model, ways and mechanisms of interaction and collaborative development of urban and rural education [9]. Modern information technology can be distributed in different regions linking computer organically to form a mutually interconnected and individually independent information exchange and resource sharing system. The sharing of information resources can greatly narrow the gap between urban and rural educational resources and provide equal conditions for urban and rural students [10].

\subsection{To Better Exchange Learning Between Urban and Rural Students}

Through the construction of our learning platform, it will solve the problem that urban and rural students cannot carry out large-scaled and in-depth exchange activities, and the problem that a lasting and stable relationship between students is difficult to form and the learning resources in urban and rural areas cannot be fully shared. Urban students acquire new information faster and in a wider range, while rural students are more accessible to first-hand agricultural knowledge and rural culture. The online learning community brings together the resources of contribution of members. Through the Moodle platform, the urban and rural students can communicate and implement the corresponding interactive tools such as BBS, live chat, E-mail, blog, etc. to deepen the understanding of diverse cultures [11]

\subsection{To Better Exchange Learning Between Urban and Rural Teachers}

Rural teachers, confined by the teaching conditions, geographical environment and other factors, have been in a relatively closed state for a long term, while urban teachers are accessible to a wealth of teaching information and latest educational results. Moodle provides an open platform for the exchange between urban and rural teachers: rural teachers can learn from excellent urban teachers, teaching ideas; while excellent urban teachers can help rural teachers to widen their thinking and broaden their teaching horizons. For urban teachers, through cooperation with rural teachers in teaching and research, they both can not only improve the research ability, but also explore further in teaching practice. Moodle is actually an invisible "bundled" teacher training model to optimize the teaching structure of rural teachers, promoting the urban and rural teachers to communicate and learn from each other, for the support of providing a better learning community for urban and rural teachers [12].

\section{THE DESIGN}

\subsection{Principles of Design}

Principle one: Proceeding in an orderly way. Different from traditional learning model, the network learning model is based on the computer information technology, and makes use of Moodle to create virtual learning space to share resource and realize effective interaction and collaboration between teachers and students, which imposes different requirements on teachers, parents and other participants. The effective operation of the network learning community needs not only good hardware facilities, but also a good community culture; therefore, educators, learners and managers need some time to adjust and adapt to the new learning model, and gradually form a good network of learning community culture to constantly improve the network learning effect.

Principle two: Student-oriented. To change the traditional teacher-oriented teaching model, teachers should gradually evolve themselves as mentors, supporters, solver and cooperators, while students should be centered on [13]. Data can be saved to record students' learning behaviors, such as login \& exit time, browsing \& editing operations, and exchanges between peers and teachers in learning process. Through the analysis an individual student can be described in terms of character, learning style, learning preferences, learning motivation and other learning requirements [14]. Thus, it can be targeted to prepare the lesson, teaching programs, and set the teaching content, discussion topics, and interactive links 
accordingly.

Principle Three: Convenient and easy to operate. The Moodle interface should have the unified style, clear navigation, reasonable layout. More importantly, the interface of the operation must not be too complicated, which is the top priority for designing platform module and one of the key factors to attract students to learn. Otherwise, students may not only be misnavigated in practice, affecting the learning effect, but also gradually lose the enthusiasm, interest, and even learning confidence [15].

\subsection{Operation Form}

Online and offline, synchronized. Building a Moodle-based Online Learning Community includes two aspects: First, Moodle platform should be fully used to create online collaborative learning between urban and rural students, including "students-students" network learning exchange and "teachers-students" network teaching. Second, through the "summer camp", "learning tour" and other offline forms, "face to face" communication directly facilitates urban and rural students to experience different learning and life culture and enhances the cohesion of network learning community.

Dynamic evaluation and real-time adjustment. The most prominent feature of the Moodle platform is that teachers can monitor students' use of the platform for learning by tracking learners' behaviors. For instance, a teacher can observe students' participation in a teaching module, check students' study report, including visiting number, time and place of an individual student. The data of these reports can be dynamically generated in the form of charts, so that teachers could use Excel and other tools to conduct in-depth analysis of the data to fully assess student learning situation dynamically and in real time [16]

\subsection{Functions}

Curriculum Management Function: share course resources. Separate curriculum file storage spaces are designed for each course in Moodle; by so doing teachers can easily upload a variety of teaching resources, including the common micro-class video, flash animation, teaching courseware, teaching notes, etc. Course resources refer to a variety of teaching resources or links to the URL, as well as simple text editing and direct entry in the web format. In the pre-class study or research study, students can use curriculum resources in learning at any time. For teachers, these curriculum resources also play an important role for teaching research and learning exchange.

Chatroom function: Online synchronization of teaching and learning seminars. Chat room can provide smooth, synchronized text interaction, and support URL address, emoticons, images and other formats for teachers and students for the real time discussion and exchange of course contents. The system records all the discussion and is open for teachers and students. When students encounter difficulties in learning, teachers can implement one-to-one or one-to-more online simultaneous teaching on the Moodle.

Upload homework function: asynchronous teaching. The system allows students to upload $500 \mathrm{MB}$ of homework in file format and automatically record the time when students submit their assignments. The system can also feedback teachers' criticism, results, and comments to the students.

Discussion area function: group collaboration and learning. Teachers can set some limits in the discussion area. For instance they can set that students can respond to discussion and post articles, but cannot initiate a discussion; whether the article posted in the discussion area can be directly sent to each student's e-mail or not. In research activities, teachers can heterogeneously group students across the class, and create discussion forums for each group on the Moodle. Focusing on the relevant topics, students will upload the valuable information to the discussion area, thus enriching the learning resources. Students can gain collective sense of honor and sense of belonging by sharing knowledge and exchanging discussions [16].

Testing function: teachers assess the state of students' learning. The Moodle has a multi-functional online test system that supports multiple choices, judgment, blank filling, cloze, matching and other online test tasks [17]. Teachers can set questions randomly by manual or by automation or by both; the quiz supports automatic scoring, time limit and other functions. Questions and answers can be displayed at random to reduce exam cheating. In students' research activity, teachers can set up the question bank for relevant courses on the Moodle, having students assessed at the given time span to test students how they use the resources of the Moodle for research learning.

Learning activity reporting function: teachers can monitor students' learning process. The student activity report is a functional section where teachers track students' learning records on the Moodle. Activity reports include four function blocks: summary reports, full reports, today's log and all logs. Teachers, by checking students' learning activity report, can track the students' learning process, understand their interests in the course and the attitude towards the study and then capture and discover the students' learning. Teachers, at different stages, can adjust learning situation and feedback to the students according to the activities of the report, so that students could see their gap with others, and accordingly adjust their learning strategies in time.

\section{CONSTRUCTION}

In the network environment, the learning community is mainly composed of four parts: students, teachers, learning resources and interactions. In the learning community, students are divided into urban and rural ones; teachers into urban and rural ones. Based on the Moodle, a model of online learning community between the urban and rural students is built, as shown in Fig. 1.

Learning interactions between Students-Students. It includes students' internal learning interaction not only in urban schools and rural ones respectively, but between urban students and rural ones. A survey on urban and rural students' learning and life requirements by Wang Jixin et al. shows that more than $90 \%$ of the students agree to build convenient communication sites, and wish to understand and experience different life in urban or countryside area through the website, and then exchange their ideas in study and life [11]. It can be seen that both urban students and 
rural students desire to communicate with each other strongly.

On the Moodle platform, urban and rural students can work together and discuss problems in their assignments, and ask teachers for help. Besides, students can speak their minds freely and exchange their ideas extensively. They can also record and communicate their feelings as well as emotions in learning in a form of diary. In order to promote better communication between urban and rural students, and enhance group cohesive force, the platform sets up the "life sharing" column where students can share their life stories in the "urban and rural life" forum with words and pictures, and exchange the different lifestyles and cultural experience. Meanwhile, facilitated by teachers, students can sponsor collective activities regularly, giving themselves a chance for face-to-face communication. Take $X$ city for an example, at least two activities can be organized in the city annually. On the one hand, "one day tour to $X$ city" summer camp can be possibly organized during summer vacation with the urban students being tour guides. In the evening, rural students can be accommodated in urban students' homes with the aim to better experience the urban life. On the other hand, "autumn harvest experiencing" activities during the national day holidays can be organized in order to make urban students better experience farming life by doing farming work during the day, and by home staying with rural family in the evening [11].

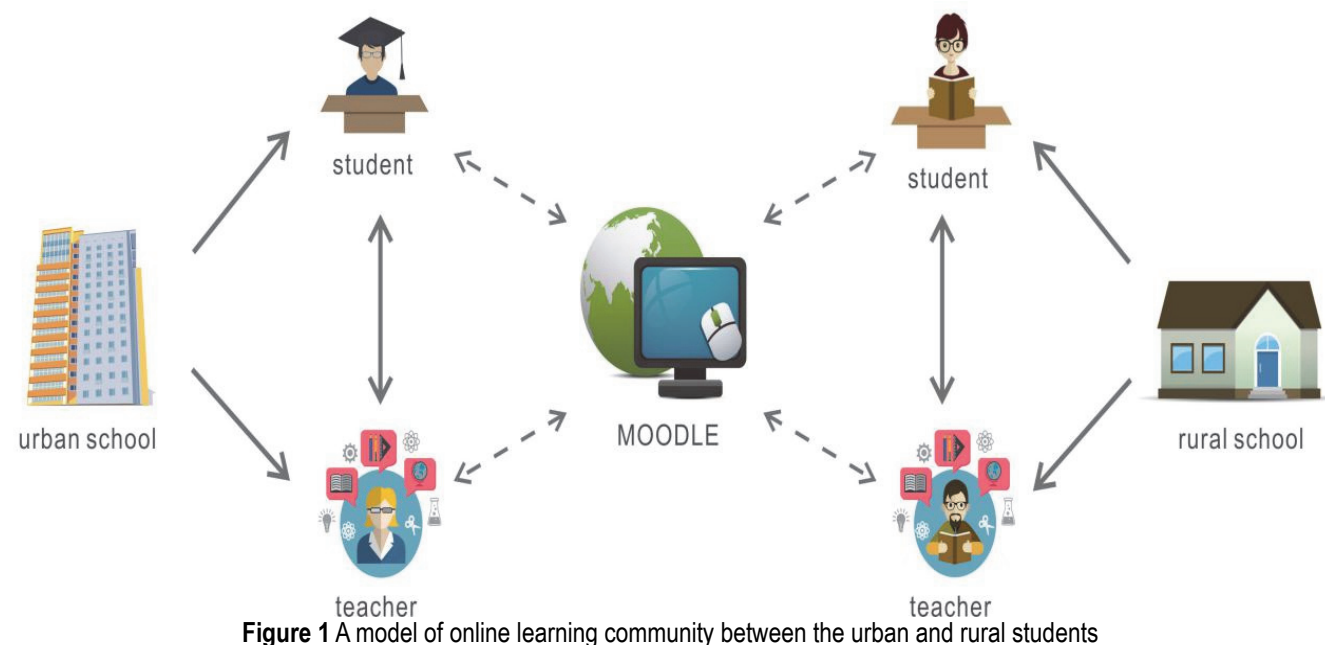

Figure $1 \mathrm{~A}$ model of online learning community between the urban and rural students

Online teaching between Teacher-Students. In the traditional teacher-oriented model, students have no choice but accept what is taught passively. As a result, they have few opportunities to raise question. In a long run, the students' ability to innovate would be faded away. While on the Moodle platform, teachers and students are equal; when facing teachers in virtual world, students' psychological pressure is considerably reduced [18]. In this way, they can share knowledge on the Internet freely through collaborative learning, and can promote knowledge absorption through communication and reflection. Obviously, online teaching has more advantages in cultivating students' innovative ability. Moreover, when some teachers are not competent to some specific teaching contents which are more suitable to implement through the platform, teachers and students thus can implement remote synchronous or asynchronous teaching on the platform. For example, more competent urban teachers can teach those rural students through the platform. Meanwhile, as for some specific teaching contents, rural teachers could also make full use of the platform and implement non faceto-face network teaching to urban students.

Teaching and research communications between Teachers-Teachers. It includes exchanges on teaching and research between urban and rural teachers. According to the demand, teacher learning forum is set up on the Moodle platform, which is divided into six sections: "theoretical basis", "learning resources", "teaching reflection", "training plan and summary", "teaching case and research paper" and "research project". Corresponding resources are shown in each section. For instance, in the "teaching reflection" section, one teacher is responsible for collecting excellent reflections and experience in teachers' blog, and then releasing it on the platform [19]. Under the support of "blog", "wiki" or "discussion" modules on the Moodle platform, a peer coaching relation between teachers is formed. For instance, by using the "blog" module, teachers can learn from each other in the "teaching experience exchanges", "experience and exchange", "teaching essays" column where urban and rural teachers can benefit a lot in obtaining knowledge, experience and thoughts from mutual discussion [20].

\section{APPLICATION AND FEEDBACK}

After the construction of the platform was completed, its practical use has been put to test on the urban and rural students. Results show that some remarkable changes have taken place among students in the two schools. Through the questionnaire survey and observation, some positive feedback from students, teachers, administrators as well as parents are obtained. These changes and feedback are analyzed in detail as follows.

\subsection{Significant Changes}

Educational resources sharing between urban and rural schools. Once, there existed a lack of effective interaction between urban and rural schools. Meanwhile it has become possible to share many resources for urban and rural schools since the operation of the platform, including curriculum resources, teacher resources, e-resources as 
well as management experience. For instance, some teaching resources in rural schools are relatively weak; by making full use of good teaching resources on the platform, students in these schools can have classes under the teachers' management and assistance. This course is so called "micro class" or "MOOC". However, not only do rural schools benefit a lot, but rural schools could make themselves practical teaching bases for urban schools.

Cultivation of students' self-learning abilities. Different from the traditional teacher-oriented model, the platform is committed to the "student-oriented" one in which teachers just act as a guide, supporters and facilitators, while students give full play to their initiatives in each module, actively participate in the learning process, and effectively cultivate students self-learning abilities and self-discipline. Moreover, with the interactive features of the Moodle learning platform, it is possible for students to collaboratively learn from each other.

Urban and rural students' obtaining of different cultural experience. The platform provides a variety of communication ways for the urban and rural students, online and offline. Through in-depth exchanges and practical activities, urban and rural students could experience various lifestyles and cultural traditions of cities and countryside, enrich their life experience and strengthen their understanding of the society, which is conducive to students' all-round development.

Achieving diversified learning evaluation. Previously, the final examination as a form to evaluate students' learning situation was single, which is not conducive to evaluate students comprehensively. However, since the operation of the platform, not only is the process evaluation provided by the track record on students' learning behaviors, but also summarized evaluation is formed through daily homework, organized assessment and various activities. Meanwhile, there are also selfcomments and the mutual assessment of learning companions. The diversified learning evaluation, with more experience and harvest to the course study, provides the basis for the improvement of the students' follow-up study and the teachers' follow-up instructional design.

\subsection{Favorable Feedbacks}

In order to investigate students and teachers' degree of satisfaction towards the platform, a platform satisfaction questionnaire was designed. From the questionnaire survey results, most respondents were rather satisfied with the platform. For teachers, the platform makes the teaching resources sharing possible which is not only beneficial to teachers' development and teaching effects, but also effective to support the network community. Meanwhile, teachers believe that through the network teaching, the teacher-oriented teaching model was replaced by studentoriented teaching model, cultivating students' self-learning ability, and inspiring students to learn enthusiastically. For students, the platform makes boring learning interesting because they can exchange and share their opinions freely on the platform so that they can experience different cultures between the city and village, achieving common learning and common progress purposes. For the education managers, the platform enables the sharing of urban and rural educational resources, providing equal learning conditions for urban and rural students, which contributes much to the mutual development of education.

As can be seen from the survey, however, there are also some problems. For teachers, they think the operation of the platform consumes much energy, including courseware preparation, micro-video production, etc. For students, their ability to utilize information and technology needs constant improving. For the education department, it requires a higher level of educational information, especially in rural schools since the platform is based on the Moodle.

\section{CONCLUSION}

The online learning community of urban and rural students on the Moodle platform has the characteristics of interaction, sharing and collaboration. The construction and application of the platform can help the students in urban and rural areas to carry out in-depth learning exchange and practice activities, share learning resources and enhance collaborative learning ability. It can help to change the traditional "teacher-oriented" learning model into "student-oriented" one and advocate "learningoriented" learning model, greatly cultivating the students' initiative of learning. Teachers in urban and rural areas can also use the platform to carry out teaching and research exchanges and continuously improve their abilities to teach. In addition, it is beneficial to narrow the gap between urban and rural areas so that students can obtain high quality educational resources and further promote the mutual educational development.

\section{Acknowledgments}

This work is supported by "research on the cultural integration of new social strata under the guidance of socialist core values" (19BKS168), a general project of National Social Science in 2019.

\section{REFERENCES}

[1] Ministry of education of the People's Republic of China. Education Informatization Decade Development Plan (20112020), 2012-3-20.

[2] Jun, H. \& Jing, L. (2006). Open Network Teaching PlatformMoodle System. Information Technology Education in Primary and Secondary Schools, 1, 73-74.

[3] Juan, P., Kun, Q., \& Xiaoyan, Z. (2008). Exploring the Collaborative Learning Based on Moodle. Distance Education in China, 9, 41-45.

[4] Wang, R., Li, M., \& Ma, Y. (2006). Exploring the Network Collaborative Learning of Physics Course of Middle School Based on Moodle Platform. China Educational Technology, 8, 57-60.

[5] Yongzhi, G. (2011). Research on the Network Learning Model Based on the Theory of Learning Community. China Educational Technology, 8, 55-59.

[6] Zhirong, Z. (2011). Construction and Application of Network Learning Community Based on QQ Group. China Educational Technology, 8, 92-95.

[7] Weiting, Q. (2005). Virtual Learning Community in the Network Education. Modern Distance Education, 5, 67-70.

[8] Cunyin, L. \& Hongqi, C. (2011). Integration of Urban and Rural Education and Its Institutional Guarantee. Educational Science Research, 5, 5-9. 
[9] Qinglin, H. \& Junqiao, Q. (2012). Research on the Modernization of the Integration of Urban and Rural Education. Educational Research, 8, 4-12.

[10] Chuansui, Z. (2004). Teacher Professionalization and Reform on Teacher Training Course. Compilation of National Training Seminar Materials for Teachers and Education Administrators in Colleges and Universities, 2734.

[11] Jixin, W. Ting, X., \& Shumeng, L. (2008). Practice and Thought on Constructing the Network Learning Community of Rural and Urban Students. China Educational Technology, 3, 73-75.

[12] Caiping, X. \& Qimin, F. (2007). Rural-Urban Integration of Teacher Resource Allocation in the Information Environment: Theory and Conception. E-education Research, 4, 11-13.

[13] Lin, P.-C., Lu, H.-S., \& Fan, S.-M. (2014). Exploring the Impact of Perceived Teaching Style on Behavioral Intention toward Moodle Reading System. International Journal of Emerging Technologies in Learning, 9, 64-67. https://doi.org/10.3991/ijet.v9i3.3500

[14] Hui, W. \& and Yudong, M. (2016). Research on Learning Support Service of Moodle Platform in Distance Education. Jiangsu Higher Education, 6, 93-95.

[15] Lanchun, Z., Weihua, S., Yan, C., \& Jing, L. (2008). Case Study of Instructional Interaction Activities Based on Moodle Platform. Open Education Research, 4, 97-100.

[16] Caiping, X. \& Dan, W. (2006). Experimental Research on the Realization of Integration of Teacher Resource Allocation on Moodle Learning Platform. China Educational Technology, $11,79-82$.

[17] Jebari, K., Boussedra, F., \& and Ettouhami, A. (2017). Teaching Information Systems Management with Moodle. International Journal of Emerging Technologies in Learning, 12, 4-16. https://doi.org/10.3991/ijet.v12i04.6183

[18] Kaicheng, Y., Xiaoying, Z., \& Bin, W. (2006). Research on Educational Theory from the Perspective of Educational Technology. China Educational Technology, 3, 9-16.

[19] Shaoqing, G. \& Minsheng, F. (2009). Construction of the New Model of Urban and Rural Interactive Teacher Cultivation with Network Learning Community. China Educational Technology, 9, 50-54.

[20] Feng, L. \& Yanhua, W. (2008). Teacher Training on Moodle Platform. Open Education Research, 5, 91-94.

\section{Contact information:}

Fei LI

(Corresponding author)

1) School of Public Administration, Hohai University, Nanjing, 211100, China

2) School of Humanities, Anhui Polytechnic University, Wuhu, 241000, China

E-mail: hongqiqingnian@163.com 